
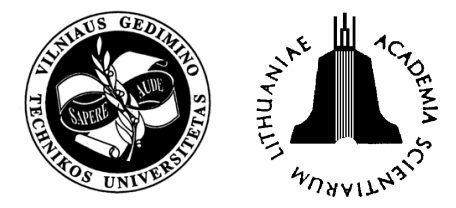

\title{
RESEARCH INTO OPERATIONAL PARAMETERS OF DIESEL ENGINES RUNNING ON RME BIODIESEL
}

\author{
Sergejus Lebedevas ${ }^{1}$, Andrius Vaicekauskas ${ }^{1}$, Galina Lebedeva ${ }^{2}$, \\ Prutenis Janulis ${ }^{3}$, Violeta Makarevičiene ${ }^{3}$ \\ ${ }^{1}$ Dept of Marine Engineering of Maritime Insitute of Klaipeda University, \\ I. Kanto g. 7, LT-92123 Klaipéda,Lithuania.E-mail:laivum@ji.ku.lt; andrius@swelbalt.lt \\ ${ }^{2}$ Dept of Computer Science of Faculty of Natural Sciences and Mathematics of Klaipeda University, \\ H. Manto g. 84, LT-92294 Klaipeda, Lithuania.E-mail: galina@ik.ku.lt \\ ${ }^{3}$ Laboratory of Chemical and Biochemical Research for Environmental Technology, \\ Lithuanian University of Agriculture, LT-53361 Akademija, Kauno r., Lithuania. \\ E-mail: agrotech@nora.lzuu.lt
}

Received 3 April 2006; accepted 4 September 2006

\begin{abstract}
The results of motor experimental researches on operational parameters of diesel engines F2L511 and A41 are presented in the publication. Change of harmful emission of exhaust gases was determined and evaluated, fuel economy and thrust characteristics of diesel engines running on RME biodiesel compared to diesel fuel. The influence of technical condition of fuel injection aggregates was evaluated for parameters of harmful emission of diesel engines running on biodiesel by simulation of setback of fuel injection in alowable range of technical conditions - the coking of nozzles of fuel injector. The complex improvement of all ecological parameters was evaluated by optimisation of fuel injection phase of diesel engines running on RME biodiesel. Objectives and aspects of further researches on indicator process of diesel engines were determined.
\end{abstract}

Keywords: biodiesel, diesel, fuel economy, thrust characteristics, harmful emission.

\section{Introduction}

Publication continues the presentation of results of common researches of Lithuanian Agricultural University and Klaipeda University into production and adaptation of biodiesel in fleets of diesel engines of Lithuania [1]. Researches are conducted under the auspices of Council of science and studies of Lithuania and performed under the framework of international project "EUREKA. BIOWASTEFUEL.E!3234". Researches are directed for local practical implementation of EU policy of application of renewable sources of energy and promotion of energy efficiency $[2,3]$. Object of researches is not only certified biodiesel - rapseed methyl ester RME (investigated in this stage of researches), but also new types of biodiesel produced from waste vegetable oil and animal fats aimed to reduce the cost price of biodiesel fuel [4].

Differences of physical chemical and thermodinamical properties of biodiesel and mineral diesel fuel influence indicator process of diesel engines and as a result change operational and ecological pa- rameters [5]. The properties of biodiesel differ depending on raw material and properties of technological process of production. Regarding the said above, most important is the evaluation of operational and ecological parameters of diesel engines running on RME produced in Lithuania. The blending of biodiesel with mineral diesel fuel is the implement to form the properties of fuel and regulate the change of indicator process, operational and ecological characteristics [6]. It is an important fact, because a desirable condition of the change of mineral diesel fuel to biodiesel in operated fleets of diesel engines is the achievement of reduction of harmful emission of exhaust gases without losses of operational parameters and special regulation of diesel engines.

The goal of the performed stage of researches was to evaluate the improvement of ecological parameters, the change of parameters of fuel economy and load of non-road diesel engines of agricultural machines and units of small energetics running on RME biodiesel produced in Lithuania and its blends with mineral diesel fuel. 


\section{Methodical aspects of researches}

Motor stand tests are performed with high speed non-turbocharged diesel engine F2L511 of wide range of application (producer JSC “Oruva ir Ko", Mazeikiai, Lithuania) and tractor purpose diesel engine A41 (producer JSC "Altaiskij motornij zavod", Barnaul, Russian Federation). Diesel engines F2L511 are produced under licence of German concern "Deutz AG" and are used in non-road trasport means, diesel generatings sets, drives of power agregates (pumps etc.). Both diesels are widely used in countries of Eastern Europe, Asia, and Africa and particularly in Western Europe. Diesel A41 according to its technical parameters and constructive solutions represents a wide fleet of morally old diesel engines of agricultural purpose, produced in ' $80 \mathrm{~s}-{ }^{\prime} 90$ s of last century, but still widely used nowadays in Lithuania and countries of Eastern Europe. Chosen objects of researches actually represent diesel engines used in Lithuania and that alows to spread the results of researches for the evaluation of effectiveness and technical reliability of diesel fleets of Lithuania running on biodiesel.

The parameters of researched diesel engines are presented in Table.

Parameters of researched diesel engines

\begin{tabular}{|c|l|c|c|}
\hline No & \multicolumn{1}{|c|}{ Parameter } & F2L511 & 1A41 \\
\hline 1 & Cylinder diameter, $\mathrm{m}$ & 0,10 & 0,13 \\
\hline 2 & $\begin{array}{l}\text { Piston stroke length } \\
S, \mathrm{~m}\end{array}$ & 0,105 & 0,14 \\
\hline 3 & $\begin{array}{l}\text { Engine displacement } \\
V_{h}, \mathrm{dm}^{3}\end{array}$ & 1,65 & 1,86 \\
\hline 4 & Compression ratio $\varepsilon$ & 17 & 16 \\
\hline 5 & Rated output $\mathrm{P}_{\mathrm{e}}, \mathrm{kW}$ & 25,7 & 14 \\
\hline 6 & $\begin{array}{l}\text { Rated break mean } \\
\text { effective pressure } \\
p_{\text {me }}, \mathrm{MPa}\end{array}$ & 0,62 & 0,85 \\
\hline 7 & Rated speed, rpm & 3000 & 1750 \\
\hline 8 & $\begin{array}{l}\text { Parameters of nozzles } \\
\text { of fuel injector }\end{array}$ & direct & direct \\
\hline 9 & Fuel injection & open & open \\
\hline 10 & $\begin{array}{l}\text { Type of combustion } \\
\text { chamber }\end{array}$ \\
\hline
\end{tabular}

Testing of fuel types: mineral diesel fuel according to standard GOST 305, biodiesel RME, certified according to standard LST EN 14214, produced in JSC "Rapsoila" (Mazeikiai, Lithuania), RME blends with mineral diesel fuel by volummetric proportions 90/10 (B10), 85/15 (B15) and 70/30 (B30).

Motor stand tests are planned and performed in wide range of load and speed: $30-100 \%$ of rated break mean effective pressure $p_{m e}$ and 65-100\% of rated speed $n_{\text {nom }}$. Important aspect of researches is modelling of different technical conditions of diesel engine. At the time of experiment a setback of aggregates of fuel injection in allowable range of tech- nical conditions was simulated. As a result, large amount of data (about 90 regimes) was collected, which allowed to evaluate on the certain level the effectiveness of application of biodiesel in diesel engines at real operational conditions: to compare parameters of diesel engine at the ideal technical conditions and with digression from ideal technical conditions - the coking of nozzles of fuel injector (further: unideal technical conditions).

Motor tests of diesels were made in certified stand, supported by automated measuring and registration devices of the main technical-economical parameters (fuel consumption, temperature of exhaust gases, load etc.) and of harmful emission of exhaust gases. To regulate the load the hydraulic brake Zöllner 20LLNE3N19A was used (0-200 N, measuring error $\pm 0,5 \%)$ controlled by computer FIPS-S486/66-FTFT-635-ES/AT-08-4SER/TM-PLU; the fuel consumption was measured by fuel feeding rate gauge PLU 401-115W/116HR (0,3-63 1/h, measurement error $\pm 0,5 \%$ ).

The emission of exhaust gases was measured by analyzer MIR 9000, meant to register continuously the harmful emission of exhaust gases, following the method of infrared absorption spectroscopy and gas filter correlation. The smallest measurement scales of harmful emission: carbon dioxide $\left(\mathrm{CO}_{2}\right)_{-}^{-}$ $0 \div 10 \mathrm{ppm}, \quad 0 \div 20 \mathrm{mg} / \mathrm{m}^{3}$, carbon monoxide $0 \div 30 \mathrm{ppm}, 0 \div 40 \mathrm{mg} / \mathrm{m}^{3}$, nitrogen monoxide (NO) $0 \div 100$ ppm (note: taking into account that NO compose about $90 \%$ of $\mathrm{NO}_{\mathrm{x}}$ emission further in the text NO will be named as $\mathrm{NO}_{\mathrm{x}}$ ), $0 \div 200 \mathrm{mg} / \mathrm{m}^{3}$, hydrocarbons $(\mathrm{CH})-0 \div 20 \mathrm{ppm}, 0 \div 25 \mathrm{mg} / \mathrm{m}^{3}$. The measurement error is within the limits of the smallest measurement scales of components. The smoke emission of exhaust gases was measured by Bosch analyzer. Measurement limits are $0 \div 10,0$ units, measurement error - 0,1 unit.

As additional for the diesel engine 1A41 (single block of diesel engine A41) the following parameters of indicator process and fuel injection were measured by using digital data analyzing station $\mathrm{H}-2000$ : pressure of gases in the cylinder of engine $p_{g}$, fuel pressure in output of high pressure fuel pump $p_{f b}$, the length of needle lift of fuel injector $h_{f}$. The measurement errors: $\pm 0,5 \% p_{g}, \pm 1 \% p_{f b}$. The measurement error of visual registration of characteristic angles of indicator diagram taking into account static synchronisation with TDC (top dead center) of sensor is $\pm 0,25 \div 0,3^{\circ} \mathrm{CA}$. Mentioned parameters of indicator process were determined by summarized $20 \div 40$ diagrams of working cycles. The harmful emission of exhaust gases was measured by gas analyzer "Quintox 9106" with following measuring errors: $\mathrm{CO} \pm 10 \%, \mathrm{NO} / \mathrm{NO}_{2} \pm 10 \%$. 
At the research of diesel $1 \mathrm{~A} 41$ comperative analysis of kinetic combustion of mineral diesel fuel, biodiesel and their blends was perfomed. It allowed to determine consistent patterns of fuel injection, processes of period of induction (processes before combustion) and of combustion. Obtained data allowed to compare and summarize parameters of characteristic phases of the indicator process, stability and repeatability of working process. Results of tests will be presented in the comming publications of authors.

\section{The ecological characteristics of diesel engines running on RME biodiesel}

The parameters of emission of harmful components $\left(\mathrm{CO}, \mathrm{CH}, \mathrm{NO}_{\mathrm{x}}\right)$ and smoke emission (SE) characteristics of load of diesel engines F2L511 and 1A41 running on mineral diesel fuel (GOST 305) are presented in Fig 1.

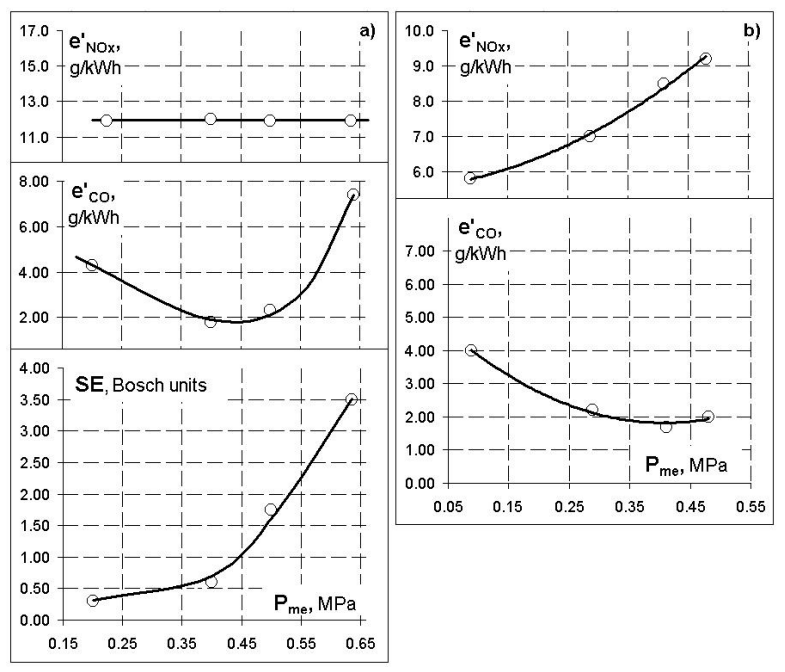

Fig 1. The ecological parameters of diesel engines: $\mathrm{a}-\mathrm{F} 2 \mathrm{~L} 5 \mathrm{II}(n=3000 \mathrm{rpm})$; b - 1A41 $(n=1750 \mathrm{rpm})$

The change of emission of $\mathrm{CO}, \mathrm{CH}$ and $\mathrm{SE}$ is characterized by comparatively low level at medium and low loads $\left(50 \div 60 \% P_{e \text { nom }}\right)$ and intensive growth by $5 \div 6$ times at rated and maximum loads (for the diesel F2L511 $n=2000 \mathrm{rpm}$ ). The main attention should be paid to rated loads because of the mentioned reason. Emission level of nitric oxides $\mathrm{NO}_{\mathrm{x}}$ changes very little depending on load. At the same time for the identical $p_{m e}$ decrease of speed of diesel engine F2L511 from $n=3000 \mathrm{rpm}$ to $n=$ $2000 \mathrm{rpm} \mathrm{NO}_{\mathrm{x}}$ emission increases by $\sim 30 \div 35 \%$. For the evaluation of operational effectiveness of biodiesel regarding $\mathrm{NO}_{\mathrm{x}}$ emission it is neccessary to analyse changes in all range of loads.

As it could be expected the technical condition of fuel injection aggregates (the quality of fuel injection) significantly influences the ecological parameters of emission. For instance, the following increase of parameters of harmful emission of the diesel engine F2L511: $\delta e_{\mathrm{CO}}-65 \%, \delta e_{\mathrm{CH}}-150 \%, \delta e_{\mathrm{NOx}}-$ $25 \%, \delta \mathrm{SE}-15 \%$. The evaluation of operational effectiveness of biodiesel is made for the ideal technical conditions of fuel injector and for partly coked fuel injector (unideal technical conditions), the results are presented in Fig 2.

Determined level of harmful emission of exhaust gases correlates well with the known results of analogous data of experimental tests and theoretical calculations [7]. The increase of mass of oxygen in the composition of biodiesel from $1 \%$ up to $12 \%$ compared to mineral diesel fuel influences the decrease of stoichieometric air/fuel ratio from 0,495 to $0,433 \mathrm{kmol} / \mathrm{kg}_{\text {fuel }}$, and for the constant other external conditions influences the increase of excess air ratio $\lambda$. Better characteristics of selfignition of RME (cetane number: 51,6 for RME compare to 46 for mineral diesel fuel) positively influences the reduction of intensiveness of heat extraction (the speed and quantity of heat) in primary kinetic phase of combustion which is characterized by the formation of products of non-complete combustion. It also increases the heat extraction in the main phase of combustion - diffusion combustion - because of higher $\lambda$ and presence of fuel oxygen in the combustion process. Diffusion combustion phase is characterized by further combustion of products of noncomplete combustion, which forms in the kinetic phase of combustion. As a result the reduction in intensiveness of formation and combustion of $\mathrm{CH}$, $\mathrm{CO}$ and $\mathrm{SE}$ in the main phase of combustion was noted, which causes the total reduction of harmful emission when running on biodiesel. On the other hand the emission of $\mathrm{NO}_{\mathrm{x}}$ increases by $10 \div 13 \%$ [8], which is of thermal origin and depends on the concentration of reagents $\mathrm{N}_{2}$ and $\mathrm{O}_{2}$ and temperature in the zone of combustion.

Analogical degree of the change of harmful emission $\delta e_{\mathrm{CO}}, \delta e_{\mathrm{CH}}^{\mathrm{C}}, \delta e_{\mathrm{NOx}}, \delta \mathrm{SE}$ is observed for both tested diesels at the partial regimes of load, independently on technical condition of fuel supply aggregates. The error of experimental data from generalized curves is about $\pm 3 \div 5 \%$. Obtained results allowed with high accuracy to extrapolate data of stand tests with biodiesel and its blends with diesel fuel, for the operational conditions of diesel engines with similar construction, and organisation of working process for solving the tasks of technical reliability.

Functional dependences of relative errors of load $\delta e^{{ }_{\mathrm{CO}}}, \delta e_{\mathrm{CH}}, \delta e^{{ }_{\mathrm{NOx}}}=f\left(p_{m e}\right)$ are " $S$ " form: $\delta e^{{ }_{\mathrm{i}}}$ changes little at the low and medium regimes of load (up to $40 \div 50 \% P_{e \text { nom }}$ ); for the load over $50 \%$ $P_{e \text { nom }}$ the intensive growth and further stabilization at the regimes $90 \div 100 \%$ of $P_{e \text { nom }}$ is observed.

Emission of carbon monoxide CO. Application of biodiesel $\mathrm{B} 30$ reduces $\mathrm{CO}$ emission of exhaust gases by 
$8 \div 12 \%$ for the researched load up to $50 \%$. $\delta e^{6} \mathrm{CO}$ intensively increases up to $30 \div 37 \%$ for the high loads. The reliance $\delta e^{6} \mathrm{CO}=f\left(p_{m e}\right)$ remains the same and for pure biodiesel B100 equidistancially in function of $p_{m e}$ moving towards higher reduction values of $\mathrm{CO}$ emission. $\delta e_{\mathrm{CO}}^{6}$ values for the identical regimes allow $p_{m e}$ to state that reliance of influence of RME part increasing in the blend to the reduction of $\mathrm{CO}$ emission is non-linear. The reduction degree of $\mathrm{CO}$ emission for the biodiesel $B 100$ is $1,5 \div 1,6$ higher than for the biodiesel $B 30$ when the concentration of RME increases by three times. This proportion remains in the whole researched range of $p_{m e}$. The established proportions form the base for the prognosis of operational effectiveness of biodiesel application (by the integral parameters of emission of operational cycle) at the limited quantity of experimental data.

Emission of hydrocarbons CH. It is observed that analogical " $S$ " form reliance of $\mathrm{CH}$ emission changes on load $\delta e^{6} \mathrm{CH}$. The change of emission in case of application of biodiesel B30 is about $20 \%$, reduction increases up to $50 \%$ for the rated regime of load. The effect of application of RME biodiesel $B 100$ is the reduction of emission by $65 \%$ for all researched range of load and it is $1,2 \div 1,5$ higher than of biodiesel $B 30$.

Smoke emission SE. The change of reduction of smoke emission of diesel engine running on biodiesel differs little from $\delta e^{6} \mathrm{CO}$ and $\delta e^{6}{ }_{\mathrm{CH}}$. Function $\delta \mathrm{SE}=f\left(p_{m e}\right)$ is " $U$ " form with maximum at the regime of medium load. The reduction of smoke emission in exhaust gases for the biodiesel $B 30$ is $50 \div 55 \%$ at the regime of medium load and $25 \div 30 \%$ at the regimes of low and rated loads (Fig 2). Maximum effect of reduction of smoke emission for the biodiesel $B 100$ makes $75 \%$, reliance $\mathrm{SE}_{B 100} / \delta \mathrm{SE}_{B 30}$ is $1,5 \div 1,8$, respectively.

It is important to note that absolute reduction of smoke emission is just as high as high is the load. RME biodiesel analogically influences emissions of carbon monoxide and of hydrocarbons.

Emission of nitric oxides NO$_{\mathbf{x}}$. The reliance of emission of nitric oxides $\mathrm{e}_{\text {NOx }}$ on load $p_{m e}$ is analogical to reliances of $\mathrm{CO}$ and $\mathrm{CH}$ emissions but with the difference that $\mathrm{NO}_{\mathrm{x}}$ emission increases with application of RME biodiesel. Taking into account the full character of function $\delta e^{6}{ }_{\mathrm{NOx}}=f\left(p_{m e}\right)$ (Fig 2) the increase of absolute and relative $\mathrm{NO}_{\mathrm{x}}$ emissions is observed at regimes of nearly rated loads $\left(85 \div 100 \% P_{\text {e nom }}\right)$ and makes $10 \div 12 \%$.

The intensiveness of $\delta e^{6}{ }_{\text {NOx }}$ decreases when running the diesel engine at the regimes of medium load, whereas at the regimes of low load the level of emission is equal to the emission of mineral diesel fuel. Proportion $\delta e_{\text {NOx } B 100} / \delta e^{c}{ }_{\text {NOx B30 }}$ for the regimes of medium and rated loads is $1,3 \div 1,4$.

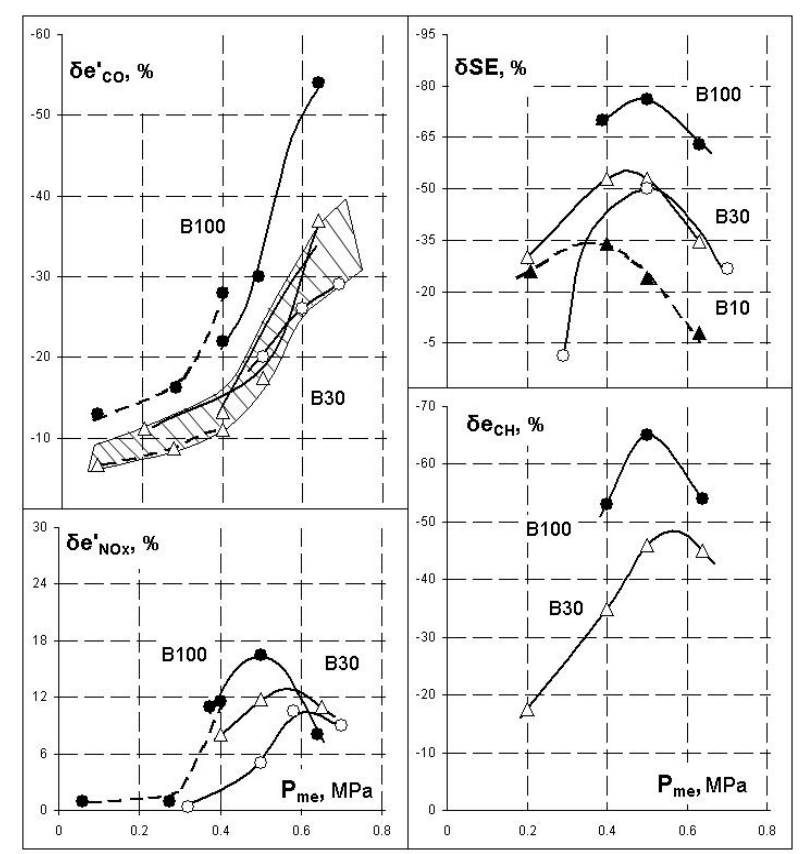

Fig 2. Relative errors of ecological parameters of diesels F2L511 and A41 at transference from work on mineral diesel to biodiesel

- B100 (F2L511, $n=3000$ rpm, unideal technical condition);

- $-\mathrm{B} 100$ (1A41, $n=1750 \mathrm{rpm})$;

$\triangle-\mathrm{B} 30$ (F2L511, $n=3000 \mathrm{rpm}$, unideal technical condition);

$-\triangle-\mathrm{B} 30(1 \mathrm{~A} 41, n=1750 \mathrm{rpm})$;

$-\mathrm{O}-\mathrm{B} 30$ (F2L511, $n=2000 \mathrm{rpm}$, unideal technical condition);

B30 (F2L511, $n=3000$ rpm, ideal technical condition);

$-\mathbf{A}-\mathrm{B} 10(\mathrm{~F} 2 \mathrm{~L} 511, n=3000 \mathrm{rpm}$, unideal technical condition)

Summarising we can declare, that influence of biocomponents on harmful emission of exhaust gases is non-linear. The increasing of RME part in biodiesel blend up to 3 times from $B 30$ to $B 100$ improves $\mathrm{CO}, \mathrm{CH}$ and $\mathrm{SE}$ emission moderately, just by $1,5 \div 1,6$ times, $\mathrm{NO}_{\mathrm{x}}$ emission increases by $1,3 \div 1,4$ times.

Performed research confirms the fact that it is expedient to use biodiesel and mineral diesel fuel blends with volumetric proportion up to $30 \%$ of RME concentration in operational conditions with regard to ecological parameters. Significant reduction of harmful emission is achieved at the operational regimes of low and medium loads: $\mathrm{CO}-$ $30 \div 35 \%, \mathrm{CH}-50 \%, \mathrm{SE}-50 \div 55 \%, \mathrm{NO}_{\mathrm{x}}$ emission increase does not exceed $10 \div 12 \%$. 


\section{The complex improvement of ecological parameters by optimization of fuel injection phase}

Application of biodiesel without additional regulation of diesel engine does not ensure improvement of all ecological parameters, compared to reduction of emission of $\mathrm{CO}, \mathrm{CH}$ and $\mathrm{SE}$ and the increase of $\mathrm{NO}_{\mathrm{x}}$ emission is observed as well. An experiment of optimization of fuel injection phase was done for the complex improvement of all harmful components in exhaust gases and particularly of $\mathrm{NO}_{\mathrm{x}}$. The regulation of fuel injection phase in operational conditions does not make any technical difficulties and that is why it is considered as one of the real means of improving the effectiveness of biodiesel in operation $[9,10]$.

The evaluation of influence of fuel injection phase $\Phi_{f i}$ on the ecological parameters is made for diesel engine A41 in regime: $n=1750 \mathrm{rpm}$ $\left(P_{m i}=0,8 P_{m i}\right.$ nom $)$ running on mineral diesel fuel, biodiesels B30 and B100 (see Fig 3). There was researched range of change of $\Phi_{f i}: 24 \div 30 \mathrm{deg}$ BFTDC (before top dead center) when typical $\Phi_{f i}$ for this diesel is $27^{\circ}$ BFTDC.

The reduction of fuel injection phase $\Phi_{f i}$ reduces the intensiveness of combustion in the primary kinetic combustion phase and moves it towards extraction stroke compensating the improvement of combustion in case of application of biodiesel (with regard to indicated coeficient of effectiveness). This positively influences the reduction of $\mathrm{NO}_{\mathrm{x}}$ emission, where the biggest part of it forms in the kinetic combustion phase until the moment when the maximum preasure $P_{\max }$ of cycle is seeked [11]. On the other hand, the emissions of products of non-complete combustion increase, first of all $\mathrm{CO}$ and SE emissions. That must be evaluated at reduction of $\Phi_{f i}$ by keeping positive the achieved improvement of harmful emission of diesel engine running on biodiesel. The object of this stage of researches is to evaluate the possibility of compensation of $e_{\text {NOx }}^{c}$ increase by reducing $\Phi_{f i}$ and keeping improvement of other ecological parameters.

Identical linear character of the change of harmful emissions is determined for all kinds of fuel: $e_{\mathrm{CO}}$ and $\delta e_{\mathrm{NOx}}^{c}=f\left(\Phi_{f i}\right)$. The increase of CO emission recalculating it for change of $\Phi_{f i}$ by $1^{\circ} \mathrm{CA}$ for the mineral diesel fuel and biodiesel $B 30$ was $3 \%$, for biodiesel $B 100-2 \%$. At the same time reduction of $\mathrm{NO}_{\mathrm{x}}$ emission $\delta e_{\mathrm{NOx}}^{c}=f\left(\Phi_{f i}\right)$ was $3 \div 4$ times higher: for the mineral diesel fuel and biodiesel $B 100-8 \%$, for the biodiesel B30 - $11 \%$ calculating for change of $\Phi_{f i}$ by $1^{\circ} \mathrm{CA}$. The main task of opti- misation is ensured: $e_{\mathrm{NOx}}^{\epsilon}$ reduction is higher than increase of $\delta e^{6} \mathrm{CO}$. For example: reduction of fuel injection phase by $2^{\circ} \mathrm{CA}$ allows fully compensate $\delta e^{6}{ }_{\text {NOx }}$ of diesel engine running on biodiesel $B 30$. Prospective increase of CO emission is only $6 \%$, so overall positive effect of application of biodiesel $B 30$ is ensured. The effect of application of biodiesel $B 100$ is higher (see Fig 3 for the near-reated loads $30 \%$ and $50 \%$ ). The reduction of fuel injection phase $\Phi_{f i}$ also positively influences the reduction of mechanical load and reliability of parts of cylinderlinear group.

The increase of important operational parameter specific fuel consumption $b_{e}$ seeks only $2 \%$. It is expected, that positive effect of $\Phi_{f i}$ reduction remains for low and medium loads related to earlier determined characteristic of qualitative change of $\delta e^{c_{\mathrm{CO}}}, \delta e^{{ }_{\mathrm{CH}}}, \delta D, \delta e_{\mathrm{NOx}}=f\left(p_{m e}\right)(\mathrm{Fig} 2)$.

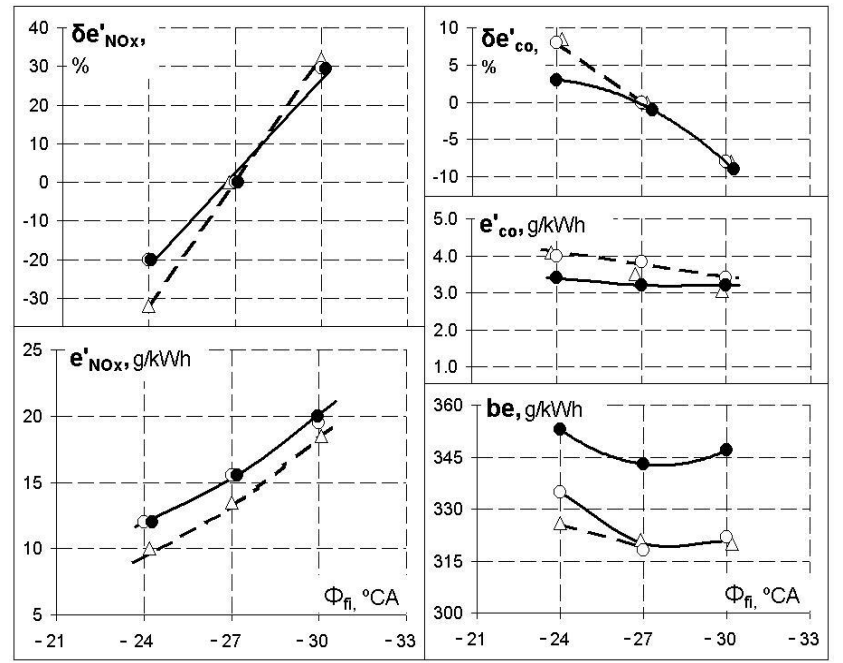

Fig 3. Influence of fuel injection phase of diesel engine A41 on ecological parameters $\left(n=1750 \mathrm{rpm} ; p_{m i}=0,68 \mathrm{MPa}\right)$ : $-\bigcirc$ - mineral diesel fuel; - - biodiesel B100; $-\triangle$ - biodiesel B30

Summarising we can state, that the reduction of $\Phi_{f i}$ by approximately $2^{\circ} \mathrm{CA}$ (that can be made without any technical problems in operation) allows to seek overall complex reduction of all parameters of harmful emission of exhaust gases, and $\mathrm{NO}_{\mathrm{x}}$ in that case, of diesel engines running on RME biodiesel.

\section{The fuel economy of diesel engine running on RME biodiesel}

Also, not less important aspect of biodiesel application in operating fleets of diesel engines is the change of its fuel economy. The differences of lower heating values $H_{u}$ of mineral diesel fuel and RME biodiesel must be evaluated for the comparative 
analysis of fuel economy. The quantity of heat $H_{u}$ extracted during combustion of $1 \mathrm{~kg}$ of RME biodiesel is by $12,5 \%$ lower than of mineral diesel fuel: $37200 \mathrm{~kJ} / \mathrm{kg}$ compared to $42470 \mathrm{~kJ} / \mathrm{kg}$. Consequently, it is purposeful to operate with two characteristics of fuel economy: specific fuel consumption $b_{e}$, determined by factual mass of fuel request to produce $1 \mathrm{~kW}$ of mechanic energy during 1 hour and equivalent specific fuel consumption $b_{e} e k v$, recalculated from $b_{e}$ by thermal properties of diesel fuel (obviously that for diesel fuel $b_{e}=b_{e} e k v$ ).

This approach fully meets the analysis of energetic balances and evaluation of application of potential energy of various fuels by its energetic equivalent widely used in practice.

The usage of parameter $b_{e} e k v$ allows to evaluate the final efficiency of energy application of alternative fuels compared to mineral diesel fuel: to evaluate overall efficiency factor $\eta_{i}$, to meet the requirements of the last initiative of EU parliament - to increase the efficiency of energy use.

There is no reason to state that mechanical overall efficiency factor $\eta_{m}$ of work on diesel fuel and biodiesel differs from the researched diesels without supercharging for the identical regimes of load ( $n$ and $p_{m e}$ ). Therefore, for the analysis of fuel economy it is possible to use both parameters: effective overall efficiency factor $\eta_{e}$ and indicated overall efficiency factor $\eta_{i}$.

Indicated overall efficiency factor $\eta_{i}$ is determined by the formula:

$$
\eta_{i}=\frac{3600 \times P_{i}}{H_{u} \times G_{f}},
$$

where $P_{i}$ - indicated power, without evaluation of mechanical losses, $\mathrm{kW} ; G_{f}-$ fuel consumption per hour, kg/h.

By applying the value of indicated specific fuel consumption $b_{i}=G_{f} / P_{i}$ equation (1) was transformed:

$$
\begin{aligned}
\eta_{i} & =\frac{3600}{H_{u} \times b_{i}}, \\
\eta_{i} & =\frac{3600}{H_{u} \times b_{e} \times \eta_{m}} .
\end{aligned}
$$

Indexes " $D$ " and " $B$ " show dependence of parameters on diesel fuel and biodiesel:

$$
\eta_{i}^{D}=\frac{3600}{H_{u}^{D} \times b_{e}^{D} \times \eta_{m}^{D}},
$$

$$
\eta_{i}^{B}=\frac{3600}{H_{u}^{B} \times b_{e}^{B} \times \eta_{m}^{B}}
$$

Assuming that $\eta_{m}^{D}=\eta_{m}^{B}$ and solving equations (4) and (5) the following expression was made:

$$
\frac{\eta_{i}^{B}}{\eta_{i}^{D}}=\frac{H_{u}^{D} \times b_{e}^{D}}{H_{u}^{B} \times b_{e}^{B}} .
$$

The value of equivalent specific fuel consumption is calculated on ratio of the lower heating values:

$$
b_{e}^{B}{ }_{e k v}=b_{e}^{B} \frac{H_{u}^{B}}{H_{u}^{D}} .
$$

By applying $b_{e}^{B}{ }_{e k v}$ the transformation of equation (6) will be as follows:

$$
\frac{\eta_{i}^{B}}{\eta_{i}^{D}}=\frac{b_{e}^{D}}{b_{e}^{B} e k v} .
$$

The relative change of $b_{e} e k v$ is identical to relative change of $\eta_{i}$, which substantiates the usage of $b_{e k v}$ for the evaluation of effectiveness of transformation of combustion heat to mechanical work on comparative fuels.

The collation of $\mathrm{b}_{\mathrm{e}}$ and $b_{e}$ ekv of diesels F2L511 and A41 running on mineral diesel fuel and biodiesel, including B100, is presented in Fig 4.

The results of 87 regimes were used for the formation of functional reliance of $b_{e}$ of diesel F2L511 with different technical conditions of aggregates of fuel supply system: at ideal technical condition which meets the requirements of technical norms and at partial cocking of fuel injectors which is common in operation.

Qualitative identical results of researches of both diesel engines are obtained:

- fuel economy practically does not change for the biodiesels B10 and B15 compared to mineral diesel fuel;

- the significant operational change of $b_{e}$ is observed for the work of diesel engine on biodiesels with concentration higher than $30 \%$;

- the change of $b_{e}$ at regimes of rated speed in the whole range of load was determined for the biodiesel $\mathrm{B} 30-2 \div 2,5 \%$, for the biodiesel B100 $-10 \pm 2 \%$. 

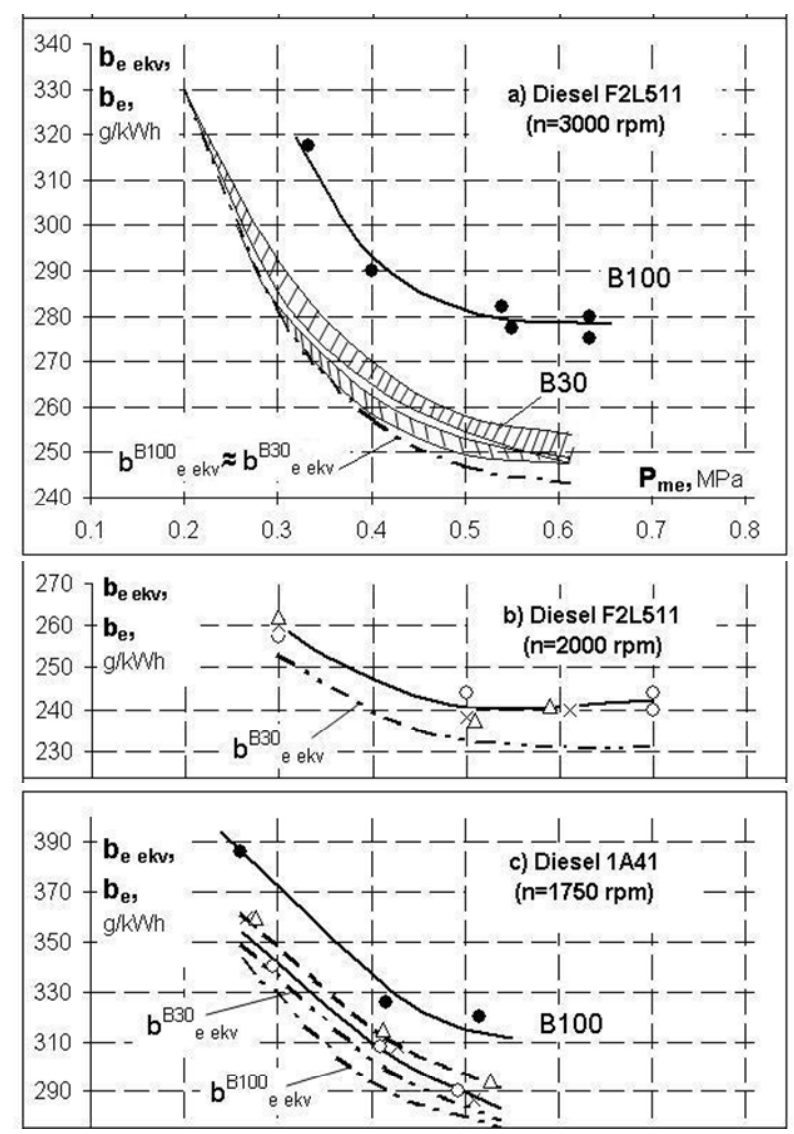

Fig 4. The change of fuel economy of diesel engines F2L511 and 1A41 by running them on RME biodiesel: $-\bigcirc-$ mineral diesel fuel ( $\square$ - summary of 87 regimes); $-\triangle$ - biodiesel B30 ( $\overparen{Z}-$ summary of 87 regimes); $-X$ - biodiesel B10 (1A41, B15);- - biodiesel B100; $\ldots \mathrm{b}_{\text {eekv }}^{\mathrm{B} 100}, \ldots . . \mathrm{b}^{\mathrm{B} 30}{ }_{\text {eekv }}$

The obvious non-linear $b_{e}$ reliance on concentration of biodiesel was determined. The optimal concentration of biodiesel is $30 \%$ with regard to deterioration of specific fuel consumption by $2 \div 2,5 \%$ and significant improvement of ecological parameters from $30 \%$ up to $55 \%$ (see chapter 3 ).

It is obvious, that improvement of ecological parameters of biodiesels with higher concentration than $30 \%$ is attended by intensive deterioration of parameters of fuel economy. The results are obtained for the constant regulation of fuel supply system. For the increase of efficiency of biodiesel application in operating diesels, it is purposeful to evaluate optimum of the main parameters of their regulation in dependence on volumetric concentration of RME and diesel fuel in the blend. In case of lack of accurate experimental data on characteristics of internal processes of diesel engine one of the ways can be the analysis of graphical reliance of $\eta_{i}$ on certain parameters of working process (excess air ratio $\lambda$, compression ratio $\varepsilon$, pressure increase ratio).
The results of calculation of $b_{e} e k v$ can be used for the confirmation of the said above. Running of diesels on biodiesel B30 increases the efficiency of heat energy by approximately $2 \%$ compared to mineral diesel fuel (Fig 4). RME part increasing up to $100 \%$ increases $\eta_{i}^{B 100}$ (reduces $b_{e}^{B 100}{ }_{e k v}$ ) by only $3 \div 4 \%$ compared to $\eta_{i}^{D}$ by using mineral diesel fuel for diesel 1A41. The reduction of $b_{e}^{B 100} e_{e k v}$ is not determined at all for diesel F2L511.

Together with parameters of fuel economy it is important to evaluate the characteristics of thrust at work in set with power user.

\section{The thrust characteristics of diesel engine running on RME biodiesel}

From the traditional viewpoint, characteristics of thrust is the reliance of torque $M_{t}$ (break mean effective pressure $p_{m e}$ ) on speed of diesel engine with maximum cycle portion of fuel $q_{\text {cycle }}$. The properties of thrust are determined by data of characteristics of load ( $n=3000,2000,1750 \mathrm{rpm})$, assuming, that any regime of load $p_{m e}$ when $n=i d e m$ can be evaluated as a certain level of boosting, limited by characteristic maximum cycle portion of fuel. At this approach the essential condition is realized for evaluation of the change of thrust for a wide range of possible boost levels by $p_{m e}$, which fully meets the objectives of these researches.

The torque for the constant speed of crankshaft is determined by mass of fuel supplied by high pressure pump, and by the efficiency of transforming heat energy in the cylinder of engine to mechanical work, which is evaluated by effective overall efficiency factor $\eta_{e}$. When $\eta_{m}=$ idem it can be evaluated by indicated overall efficiency factor $\eta_{i}$. The relative divergence of analogue of torque - of break mean effective pressure $p_{m e}$ by changing diesel fuel to biodiesel can be determined by expression:

$$
\delta p_{m e}=1-\frac{b_{e}^{D}}{b_{e}^{B} e_{v v}} \times \frac{q_{c i k l}^{B}}{q_{c i k l}^{D}} \times \frac{H_{u}^{B}}{H_{u}^{D}}=1-\frac{b_{e}^{D}}{b_{e}^{B}} \times \frac{q_{c i k l}^{B}}{q_{c i k l}^{D}} .
$$

According to equation (9) ratio of indicated overall efficiency factor is equal to ratio of equivalent specific fuel consumption, so the following expression is obtained:

$$
\delta p_{m e}=1-\frac{b_{e}^{D}}{b_{e}^{B} e_{k v}} \times \frac{\rho^{B}}{\rho^{D}} \times \frac{H_{u}^{B}}{H_{u}^{D}}=1-\frac{b_{e}^{D}}{b_{e}^{B}} \times \frac{\rho^{B}}{\rho^{D}} .
$$

Mass portion of cycle supply of fuel $q_{c y c l e}$ for plunger and distributional pumps of high pressure 
(excluding accumulative systems of fuel supply) is determined by active stroke of plunger and density of fuel. So, for the constant regulation of diesel the expression below is applied:

$$
\delta p_{m e}=1-\frac{b_{e}^{D}}{b_{e}^{B}{ }_{e k v}} \times \frac{\rho^{B}}{\rho^{D}} .
$$

Biodiesels are characterized by higher density of biodiesels $\rho$ : the density of RME biodiesel B100 $\rho_{\mathrm{RME}}{ }^{B 100}=0,89 \mathrm{~g} / \mathrm{cm}^{3}$ compared to density of diesel fuel $\rho^{D}=0,84 \mathrm{~g} / \mathrm{cm}^{3}, \rho_{\mathrm{RME}}{ }^{B 30}=0,854 \mathrm{~g} / \mathrm{cm}^{3}$. This consideration partly compensates the loss of diesel power at running of diesel engines on biodiesel by evaluating the lower heating value $H_{u}$.

The obtained data (Fig 5) reveals that application of biodiesel B30 practically has no influence on power of diesel engine. The reduction of break mean effective pressure $p_{m e}$ for the diesels without supercharging in range of boosting does not exceed $1 \%$. The running of diesel engine on biodiesel B100 is quite significant, because of the reduction of break mean effective pressure $p_{m e}$ by $5 \div 6 \%$, which forces to change regulation of high pressure pump by increasing the cycle portion of fuel $q_{\text {cycle }}$. The regulation of $q_{\text {cycle }}$ and $\Phi_{f i}$ is not neccessary at running of diesel engine on biodiesel B30. Optimal parameters remain constant not only for diesel fuel but also for biodiesel B30.

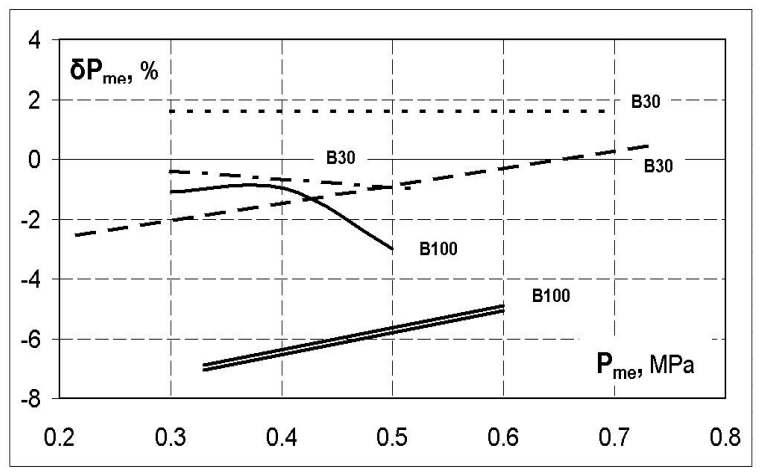

Fig 5. The change of thrust characteristics at running of diesel engines on RME biodiesel: 1A41 $(n=1750 \mathrm{rpm}$, biodiesel B100);

-....- $1 \mathrm{~A} 41$ ( $n=1750 \mathrm{rpm}$, biodiesel B30);

F2L511 $(n=3000 \mathrm{rpm}$, biodiesel B100);

$-----\mathrm{F} 2 \mathrm{~L} 511(n=3000 \mathrm{rpm}$, biodiesel B30);

- . . . . . F2L511 $(n=2000$ rpm, biodiesel B30)

\section{Conclusions}

1. The comparative motor researches of high speed diesel engines F2L511 and A41 allowed to determine emission of exhaust gases $\left(\mathrm{NO}_{\mathrm{x}}, \mathrm{CO}, \mathrm{CH}\right.$, $\mathrm{SE}$ ), the change of parameters of fuel economy and characteristics of thrust by running them on RME biodiesel and mineral diesel blends B10, B15 and B30 produced in Lithuania.

2. Qualitative identical " $S$ " - form reliances of change of harmful emissions of load $\delta_{\mathrm{CO}}, \delta_{\mathrm{CH}}$, $\delta e_{\text {NOx }}=f\left(p_{m e}\right)$ were determined for all researched biodiesels and for different technical conditions of aggregates of fuel supply system by simulation of operational conditions (partly cocking of fuel injectors):

- significant improvement of ecological parameters begins for loads over $40 \div 50 \%$ of rated load $P_{e \text { nom }}$;

- maximum effect of $\delta e^{6}$ is determined for loads of $90 \div 100 \%$ from $P_{e}$ nom .

- The obtained results form the base for evaluation of the effect of improvement of ecological parameters by running the maintained in Lithuania diesel engines on biodiesel, depending on properties of cycles of their operational load.

3. It was determined that application of biodiesel B30 is technically reliable for wide range of speed and load regimes with regard to ecological and technical-economical parameters:

- the effect of improvement of emission of exhaust gases by increasing RME part in fuel blend up to $30 \%: \delta_{\mathrm{CO}} \sim 30 \div 37 \%, \delta_{\mathrm{CH}} \sim$ $20 \div 50 \%, \delta e_{\mathrm{SE}} \sim 50 \div 55 \%$, which composes about $70 \%$ of maximum effect of possible improvement of ecological parameters by applying pure biodiesel B100;

- the increase of emission of nitric oxides for biodiesel $\mathrm{B} 30 \delta \mathrm{e}_{\mathrm{NOx}} \sim 10 \div 12 \%$, for $\mathrm{B} 100 \sim$ $17 \%$

- the deterioration of fuel economy and characteristics of thrust for the biodiesel B30 $2 \div 2,5 \%$, while for the biodiesel B100 this parameter is $10 \pm 2 \%$.

4. It was experimentally confirmed that without any significant losses of fuel economy, the reduction of regulating fuel injection phase $\Phi_{f i} \sim 2^{\circ} \mathrm{CA}$ (that can be made without any technical problems in operation) allows to reach the complex reduction of all parameters of harmful emission, and $\mathrm{NO}_{\mathrm{x}}$ in that case, at running of diesel engines on RME biodiesel. The running of diesel engine A41 on biodiesel B30 and reduction of fuel injection phase from $27^{\circ}$ BFTDC to $25^{\circ} \mathrm{BFTDC}$ allows to reduce the harmful emission compared to diesel fuel emission as follows: $\mathrm{CO}-33 \%, \mathrm{NO}_{\mathrm{x}}-10 \%$.

5. Indicator process of diesel engine using the biodiesel is characterised by the higher value of indicated overall efficiency factor $\eta_{i}$ compared to mineral diesel fuel. The increase of $\eta_{i}$ evaluated by 
equivalent fuel consumption $b_{e}^{B} e k v=b_{e}^{B} \times \frac{H_{u}^{B}}{H_{u}^{D}}$ is for $\mathrm{B} 30 \sim 2 \%, \mathrm{~B} 100 \sim 3 \div 4 \%$.

6. Further researches are planned to be directly related to determination and comparative analysis of generalized reliances of $\eta_{i}$ on main parameters of working process and characteristics of heat allocation in the cylinder at running of diesel engines on biodiesel and mineral diesel fuel.

\section{References}

1. Lebedevas, S.; Vaicekauskas, A. Research of application of biodiesel in the transport sector of Lithuania. Transport, 2006, Vol XXI, No 2, p. 80-87.

2. Directive $2003 / 30 / E C$ of the European Parliament and the Council of 8 May 2003 on the promotion of the use of biofuels or other renewable fuels for transport. OJ L 123, 2003, p. 42-46.

3. Europos bendrijų komisijos žalioji knyga „Energijos efektyvumas arba daryti daugiau naudojant mažiau“ (COM (2005) 265 final).

4. Srivastava, A.; R. Prassad. Tryglicerides-based diesel fuels. In: Renewable and Sustainable Energy Reviews, 2000, p. 111-133.

5. Van Gerpen, J. H.; Shanks, B.; Pruszko, R.; Clements, L. D.; Knothe, G. Biodiesel analytical methods. National Renewable Energy Laboratory. NREL/SR-510-36240, July 2004. 95 p.

6. Tat, M. E.; Van Gerpen, J. H. Physical properties of composition detection of biodiesel-diesel fuel blends. 2002 ASAE Annual International Meeting / CIGR XVth World Congress, Sponsored by ASAE and CIGR, Hyatt Regency Chicago, Chicago, Illinois, USA, July 28 - July 31, 2002, Paper number: 026084.

7. A comprehensive analysis of biodiesel impacts on exhaust emissions. Draft technical report. United States Environmental Protection Agency, EPA420-P-02001. October 2002. 118 p.

8. Choi, C. Y.; Bower, G. R.; Retiz, R. D. Mechanisms of emissions reduction using biodiesel fuels. Final report for the National Biodiesel Board. Engine Research Center, University of Wisconsin - Madison, January, 1997. 31 p.

9. Lebedevas, S.; Vaicekauskas, A. Improvement of the parameters of maintenance of medium speed diesels applying the motor methods. Transport, 2004, Vol XIX, No 6, p. 252-261.

10. Lebedevas, $\mathrm{S} . \mathrm{NO}_{\mathrm{x}}$ emisijos mažinimas dyzelių išmetamosiose dujose taikant motorinius metodus. Transportas (Transport Engineering), 2001, Vol XVI, No 4, p. 32-43.

11. Smailys, V.; Bykov, V. Optimization of economical and ecological parameters of diesel ChN21/21 boosting it by rated break mean effective pressure. Dvigatelestrojenije, 1990, No 4, p. 44-46 (in Russian). 